\title{
ENSINO E APRENDIZAGEM VIVENCIADOS EM UM CURSINHO POPULAR EM RIBEIRÃO PRETO-SP
}

Reijane Salazar Costa*

\begin{abstract}
RESUMO: Neste artigo uma integrante do Centro de Investigações de Metodologias Educacionais Alternativas Conexão, de Ribeirão Preto, cidade do interior paulista, relata sobre a experiência vivenciada junto a esse grupo antes de ingressar numa universidade pública. O Conexão foi fundamental para que a mesma pudesse compreender e se preparar melhor para a vida em sociedade. Enquanto membro do grupo, além dos estudos pré-vestibulares na categoria estudante, participou de diversas atividades como as aulas de capoeira, teatro, semana de Arte e Cultura, realizou viagem cultural para Ouro Preto (MG). As diversas atividades em que estava inserida agregaram inúmeros conhecimentos, além de possibilitar o ingresso da estudante em uma universidade pública. Soma-se a isso, ainda, a conscientização sobre questões educativas, sociais, econômicas, políticas e culturais que foram adquiridas ao longo da vivência naquele espaço.
\end{abstract}

Palavras-chave: Cursinho Popular; Processos Educativos; Educação.

ABSTRACT: In this article a member of the Center for Research on Alternative Education Methods (CIMEAC) in Ribeirão Preto (São Paulo, Brazil) reports her experience lived in this Center before joining a public university. CIMEAC, as a research group and a popular school, was very important to prepare the students for social life. As a student in this group, the member participated in various activities such as "capoeira" classes, theater, a week of Art and Culture, cultural trip to Ouro Preto (MG) and made popular pre-university preparatory course called Connection. The various activities in which the member was inserted added numerous knowledges, besides allowing the entry of a student at a public university. It i salso important the awareness on educational, social, economic, political and cultural questions that have been acquired over the experience in that space.

Keywords: Popular school; Education process; Education.

\section{INTRODUÇÃO}

O presente texto discute características e desafios do processo formativo de uma estudante, a partir das vivências em um curso popular,

\footnotetext{
" Graduada em Gerontologia e Mestre Educação, ambos pela Universidade Federal de São Carlos (UFSCar). Membro do Centro de Investigações de Metodologias Educacionais Alternativas Conexão (CIMEAC).
} 
denominado Conexão, localizado em Ribeirão Preto, cidade do interior paulista. Este curso possibilitou que a mesma tivesse acesso ao ensino superior público. Durante 3 anos vivenciei processos de ensino e aprendizagem junto ao Centro de Investigações de Metodologias Educacionais Alternativas Conexão (CIMEAC), participando dos projetos oferecidos pela instituição, tais como capoeira, teatro, Semana de Arte e Cultura e viagem cultural para Ouro Preto (MG). Todas essas vivências educativas contribuíram para que eu pudesse ingressar numa universidade pública. Embora todas as atividades relatadas acima tenham contribuído demasiadamente com meu processo educativo, pautarei neste artigo principalmente as características e os desafios vividos no curso preparatório pré-vestibular vestibular. O curso pré-vestibular foi a porta de entrada para que eu pudesse conhecer e participar das atividades das demais atividades oferecidas pelo Conexão.

Quando procurei o Conexão o foco inicial era conseguir ingressar na universidade. Quando estava terminando o colegial, na Escola Estadual Glete de Alcântara, localizada em Ribeirão Preto (SP), minha turma recebeu a visita de alguns membros do curso pré-vestibular Conexão. Eles foram conversar conosco e divulgar o cursinho. Na ocasião, achei a ideia interessante. Não sabia bem o que era vestibular e universidade. Mas vi neste espaço a possibilidade de continuar estudando depois de terminar o colegial. Antes pretendia fazer algum curso técnico, mas também não havia muita certeza de que conseguiria fazer. Acredito que inicialmente pensei no Conexão em vez de fazer um técnico e, como era gratuito, peguei o folder de divulgação e quando iniciou o período eu me inscrevi para participara do processo seletivo.

Consegui passar pelas diversas etapas do processo seletivo. Mas depois que conheci as demais atividades mantidas pelo CIMEAC, minhas vistas se abriram para outras possibilidades. Estava diante de um universo inovador, que pensava a educação de forma diferenciada. Os militantes desta instituição contribuíram com minha formação e com a de uma coletividade de estudantes, com características muito semelhantes, pobres, negros, advindos de escola pública, mas com sonhos e desejo de transformação das realidades opressoras que estávamos inseridos cotidianamente. Acredito que a maior contribuição que os militantes puderam me transmitir foi a de que a leitura do 
mundo antecede a leitura da palavra. Desse modo, antes de eu querer ingressar na universidade deveria compreender qual a finalidade social, política e cultural dessa concretização de objetivo.

Dessa forma, os militantes não se limitavam ao material conteudista. Eles buscavam trazer e fazer a discussão de várias temáticas baseadas em nossos contextos de vida. Buscavam, portanto, nos estimular a problematizar nossa própria realidade.

\section{CURSINHO POPULAR CONEXÃO}

A luta para ingressar numa universidade pública tem gerado uma indústria de cursinhos, os quais em sua maioria são os privados que tem altos custos financeiros. Os altos preços cobrados pelos cursinhos privados correspondem a um fator de exclusão para a classe pobre, para as pessoas que estão em situação de desemprego. Esses cursinhos visam a lucratividade, afinal operam na lógica do sistema econômico vigente.

Além dos altos preços, os cursinhos de caráter privado não levam em consideração a história de vida dos educandos, as diferentes visões de mundo que a eles estão atreladas e que seriam uma ferramenta para construção do conhecimento. Ao invés disso, excluem a classe pobre de qualquer disputa, uma vez que também não conseguem acompanhar o método de ensino que por eles é empregado, o qual é pautado na memorização dos conteúdos. Pelo funcionamento de suas atividades está apto a ingressar numa universidade aquele ou aquela que consegue decorar mais conteúdos e ao final deposita o que foi decorado nas provas do vestibular.

Frente a estas questões de exclusão e não acesso das massas populares a universidade, entre outras, é que surgiram iniciativas de cursinhos populares, que segundo Castro (2005, p.51) são "ações políticas de atores engajados em projetos e ações que têm como eixo a transformação social da realidade por meio da preparação e do incentivo às classes populares a ingressarem no ensino superior gratuito".

$\mathrm{Na}$ perspectiva de Kato (2011), os cursinhos populares surgem como centros informais que são formados por grupos de pessoas que tiveram a 
experiência de passar pela universidade, e por saber dos desencontros existentes entre os processos de formação e de acesso à universidade púbica se motivaram em contribuir para que outros tivessem oportunidade de acesso. Estes espaços são organizados por diferentes características em decorrência das diferenças em relação a sua existência e ao público atendido. Este público, por sua vez, é bastante heterogêneo quanto a aspectos de idade, escolaridade, condições socioeconômicas, e tais particularidades denotam características identitárias que são próprias a cada grupo social, embora se existam mecanismos comuns em virtude do objetivo principal, que é a aprovação nos exames de vestibulares (KATO, 2011).

Nessa perspectiva cabe destacar o curso Conexão, que em acordo com Kato (2011) propõe uma metodologia de caráter pedagógico e alternativo que se contrapõe à praticada pelos cursinhos pré-vestibulares tradicionais. Uma primeira contraposição entre o Conexão e os demais particulares diz respeito ao número de estudantes que frenquentam as aulas. No Conexão, quando eu estudei, havia aproximadamente 20 alunos na "sala". ${ }^{1}$ Estive lá por três anos (2006, 2007 e 2008). Numa pesquisa realizada por Kato (2011) esse número passa para 100 alunos por turma nos cursinhos tradicionais.

Tínhamos uma metodologia diferenciada. Os professores, os quais eram militantes de diversas áreas do conhecimento, traziam conteúdos para sala de aula que estavam relacionados temáticas do contexto público e estes eram problematizados e inseridos no ensino levando em consideração nossas realidades, enquanto estudantes advindos da camada popular, trabalhadora. Dessa forma, propunham uma aprendizagem centrada na interdisciplinaridade, a qual ocorria por meio por meio nossos planejamentos e reconstruções dos conteúdos curriculares.

Alunos e professores, todos se reuniam para planejar nossas aulas, para estudarmos um determinado texto de cunho cultural, político ou econômico. Dialogávamos em reuniões os conteúdos curriculares que deveríamos ter ao

\footnotetext{
1 No Conexão não tínhamos especificamente uma sala para aula, não tínhamos uma escola, ou um prédio com salas de aula. Tínhamos cômodos de uma casa que virava sala de aula. Funcionamos em tantos espaços, os quais foram desde casa, chácara até um espaço de patrimônio tombado. Atualmente estamos num espaço cedido por professores da Universidade de São Paulo (USP) em Ribeirão Preto (SP).
} 
longo do ano. Fazíamos diversas relações com nossa realidade, com nosso cotidiano. Muitas vezes eu saía da aula e falava: "nossa, o que tive hoje foi minha própria história contada nos livros". E aquilo fazia sentido para mim, eu realmente aprendia o conteúdo. Não estava decorando, se me perguntassem eu saberia responder o porquê disso e daquilo. Fazia sentido para mim, pois partia de minha realidade o entendimento de determinado conteúdo.

Sobre nossa organização dos conteúdos programáticos, o Conexão sistematiza os conteúdos conceituais de forma temática e transversal, os conteúdos são baseados e retirados dos principais vestibulares. A organização curricular é feita por meio de 9 temas, que são: Arte e Cultura, Ciência e Tecnologia, Transporte, Energia, Saúde, Guerra, Economia, Água e Direitos Humanos (KATO, 2011). Para cada temática, nós estudantes recebíamos o material antecipadamente para que pudéssemos estudar antes das aulas, isso ajudaria a termos mais dinamismo na sala e compreendermos melhor o que havia ficado de dúvida na hora que estávamos estudando. Mas, a maioria de nós, senão todos, muitas vezes não conseguíamos estudar antes, trabalhávamos o dia interior e não dispúnhamos de muito tempo para o estudo prévio. No meu caso, procurava estudar no horário de almoço. Tinha uma hora de almoço, comia rapidamente e me sobravam alguns minutos. Era muito difícil conseguir estudar, pois na hora em que já estava começando a me concentrar estava na hora de retornar ao trabalho. E, ao chegar no Conexão, estava num cansaço da rotina de trabalho e por muitas vezes cochilei durante as aulas.

Mas durante três anos fui na persistência e deu certo. Foi com muito sacrifício. Devido a tantas dificuldades é que muitos estudantes dos cursinhos populares desistem. Não é porque não querem lutar, resistir. O problema é que não temos condições para estudar. Andamos, andamos e parece que não conseguimos sair do lugar. Aí o sentimento de impotência nos ronda e por vezes não conseguimos manter-nos de pé diante de um sistema que quer cada vez mais nos impede de acesso.

Lembro que as aulas ocorriam de segunda a sábado, sendo que aos sábados professores e estudantes se reuniam para estudar os autores que tratavam dos temas, que foram mencionados anteriormente. Aos sábados eu saia do trabalho e ia para o cursinho. Os momentos de sábado eram 
excelentes. Me via discutindo textos de autores renomados. Conseguia compreender seus enunciados, achava aquilo formidável. O objetivo de nos reunirmos aos sábados era o de discutir o tema sob diversos olhares, em virtude de nossa equipe de trabalho. O grupo era composto por professores de muitas áreas do conhecimento, como Biologia, Química, História, Matemática, entre outros. Juntávamos esses vários olhares e podíamos ter uma visão ampla dos temas que estavam sendo propostos para o estudo.

Cabe ressaltar os professores do Conexão atuam sem remuneração. São em maioria estudantes de graduação e pós-graduação. Também contávamos com professores que atuavam no ensino básico e no superior.

Havia grandes dificuldades para que eu e meus colegas permanecêssemos no Conexão. Nossas dificuldades estavam em sermos estudantes que trabalhavam para ajudar e/ou manter o sustento da família. Por vezes tínhamos que priorizar o trabalho. Não tínhamos quem nos bancasse para só estudar, tínhamos que ralar - e muito. Não era possível fazer a conciliação entre o trabalho e os estudos e, em decorrência disso, precisávamos abandonar o cursinho e nos manter no trabalho. Outros motivos que percebia ser motivo de desistência é que no início queríamos só entrar na universidade, não percebíamos que no Conexão isso era apenas um meio (não uma finalidade). O projeto ia muito além, pois nós estávamos aprendendo a ser mais resistentes e a nos reconhecermos como pessoas de direito - e isso no início nos assustava. Estávamos acostumados a ser e a aceitar as coisas e não nos víamos questionando nada. A liberdade às vezes é assustadora. Além disso, alguns estudantes ingressantes no cursinho tinham ainda pouca maturidade. Outros não conseguiam estudar pelo método do Conexão, tinham muita dificuldade em compreender, pois ele é problematizador e não de memorização. Soma-se ainda a falta de confiança em nós mesmos, já que por vezes achamos que não tínhamos capacidade para aprender e que a universidade não era mesmo para nós. 


\section{INGRESSO E PERMANÊNCIA NUMA UNIVERSIDADE PÚBLICA}

Terminei a seção anterior dizendo que uma das dificuldades de permanecer no curso Conexão partia do entendimento de que nós, estudantes advindos da classe trabalhadora, pobre e da escola pública não tínhamos capacidade de aprender, e desse modo colocávamos em nossos pensamentos que universidade não era mesmo para nós.

Felizmente o Conexão possibilitou que esse falso entendimento fosse abandonado, porque embora tivéssemos dificuldades elas não poderiam continuar sendo entraves para nosso acesso à universidade. Com ajuda dos membros do Conexão, eu e muitos outros estudantes tivemos a oportunidade de ingressar em universidades públicas.

Em 2009, ingressei no curso de Graduação em Gerontologia na Universidade Federal de São Carlos (UFSCar). A alegria foi tremenda. Não sei o que me deixava mais feliz: ter passado na universidade ou ter a certeza que deixaria o emprego que tanto me impossibilitava de estudar. Tudo parecia muito bom, mas depois voltei para realidade. Como faria para me sustentar e continuar ajudando a manter o sustento de minha família? Com relação a nosso sustento, conseguir organizar as coisas, pois ganhei todas as bolsas existentes dentro da UFSCar (bolsa moradia, bolsa alimentação e bolsa atividade). Fazendo minha avaliação socioeconômica, as assistentes sociais viram que eu não teria como me manter sem as bolsas. Com relação ao sustento de minha família, passei a fazer bicos de garçonete e recreadora em festas infantis. Depois consegui bolsa de iniciação e as coisas foram seguindo.

A questão financeira estava encaminhada. No entanto, não era a principal que me preocupava. Minha permanência na universidade era a questão que mais me deixava tensa. Havia passado tantas dificuldades para conseguir ingressar, e depois disso tudo ainda corria o risco de ter que abandonar. Isso porque a universidade exigia muito tempo de dedicação e eu continuava precisando trabalhar. Além do mais exigia habilidades que eu não tinha até então, hoje ainda não tenho, mas estou buscando consegui-las. Era habilidades relacionadas à leitura e principalmente à escrita. Durante minha 
formação escolar não fui educada para ler e muito menos para escrever. Leitura e escrita são fundamentais dentro de uma universidade. Somava-se a isso as disciplinas de exatas que tive durante a graduação. Sempre tive muita dificuldade com exatas, durante o ensino fundamental e ensino médio realmente não consegui aprender os conteúdos e isso foi um grande problema na universidade.

A universidade exerce forte pressão sobre os estudantes com o Índice de Rendimento Acadêmico (IRA). É por meio desse rendimento que os estudantes conseguem as oportunidades de bolsas, estágios, intercâmbios, entre outros. Então havia uma disputa acirrada para tirar boas notas, ser bom, manter o IRA alto. E aí quem vem dá escola pública muitas das vezes fica em desvantagem e não dá para competir de igual para igual. Temos que nos esforçar muito mais para permanecer na universidade. Passei uns sufocos, tinha que me esforçar muito para atingir as médias. Algumas colegas me olhavam de forma diferente, querendo me diminuir. Achavam que eu não deveria estar na universidade. Mas por ter vindo de um curso pré-vestibular diferenciado, o Conexão, eu tinha mecanismos para me defender e afirmar que eu também tinha direito de estar onde estava. O Conexão havia me dado o embasamento de compreensão de cidadania. E todas as aprendizagens vivenciadas neste espaço me fortaleceram para não desanimar e não abandonar o caminho.

Embora todas os abismos existentes no processo de formação e acesso à universidade pública, consegui ultrapassar muitas das dificuldades enfrentadas na universidade. Termine a graduação no período certo, que é de quatro anos. E, diga-se de passagem, meu rendimento acadêmico estava também entre os melhores da turma.

Gosto muito de lembrar das palavras de Oliveira et. Al (2009) que diz que em diferentes práticas sociais, que "decorrem de e geram interações entre os indivíduos e entre eles e os ambientes, natural, social, cultural em que vivem" (OLIVEIRA, et al, 2009, p. 4). Assim são desencadeados processos educativos. E o Conexão foi esse espaço de prática social, onde muitos processos de ensino e aprendizagem foram desencadeados. Dessa forma entendemos que são nas práticas sociais, que "desenvolvem-se no interior de 
grupos, de instituições, com o propósito de produzir bens, transmitir valores, significados, ensinar a viver e a controlar o viver, manter a sobrevivência material e simbólica das sociedades humanas" que as pessoas aprendem e ensinam umas as outras". (OLIVEIRA, 2009, p. 4).

Minha vivencia junto ao Conexão possibilitou que eu pudesse compreende questões educativas dentro de meu próprio contexto social, construir identidade crítica e reflexiva sobre minha realidade. Dessa forma vem o entendimento de que nos formamos enquanto pessoas nas práticas sociais, quando nos colocamos numa postura crítica diante dos acontecimentos vivenciados, nos orientamos e passamos a conhecer e ver o mundo de muitas perspectivas. Nas práticas sociais nos relacionamos com as pessoas de nosso convívio social. Esta interação se dá na busca pelo conhecimento de nós mesmos e dos outros. Isso é o que aponta (COTA, 2000, p. 211):

Os conhecimentos são construídos em práticas sociais, das quais participamos, quando se integram às críticas que delas fazemos, orientam nossas ações formando-nos. Esta formação decorre de uma práxis que vamos construindo em colaboração com aqueles com quem vivemos. As práticas sociais se produzem no intercambio que as pessoas estabelecem entre si ao significar o mundo que as cercas e ao intervir nele.

A partir das vivências em que participei e nos diversos contextos culturais e sociais fui me formando enquanto pessoa e fui identificando enquanto membros de um grupo Conexão.

O Cursinho Conexão atua numa perspectiva de educação problematizadora onde o educando participa da construção do conhecimento e não é mero receptor. Neste ambiente, a educação problematizadora teve em mim a finalidade de transformação social. Acredito que minha experiência junto ao Conexão que além de me preparar para as provas dos vestibulares, me preparou para problematizar as desigualdades sociais e educacionais e para que eu pudesse permanecer na universidade.

Hoje, percebo que minha vivência no Conexão me mostrou que não é necessário estar presa aos conteúdos impostos pelas agências que organizam as provas dos vestibulares. 
No início ficava preocupada em ter conteúdos, porém, com o tempo fui percebendo que os conteúdos de Matemática, Física e Português eram importantes. No entanto, esse não era o principal motivo de eu estar no Conexão e tentar ingressar na universidade.

Quando estava no cursinho tive contato com os textos de autores como Antonio Gramsci e Paulo Freire (este, aliás, é um autor da educação). Passei a ter uma visão de mundo diferente, comecei a ter tomada de consciência de que eu vivia cotidianamente situações de opressão e não conseguia enxergar. Isso foi fundamental para que eu concluísse a graduação e em 2013 ingressasse no mestrado em Educação, também na UFSCar.

\section{CONSIDERAÇÕES FINAIS}

O presente relato de experiência buscou discutir características e desafios do processo formativo de uma estudante, a partir das vivências em um curso popular, denominado Conexão, localizado em Ribeirão Preto, cidade do interior paulista. O objetivo foi evidenciar a importância participado das atividades que são oferecidas pelo CIMEAC, onde a mesma procurou focar a experiência no curso pré-vestibular, que em sua opinião funcionou como um núcleo de acesso a espaços de transformação social, política, cultural, econômica. Durante sua permanência neste espaço ocorreram mudanças em sua forma de ver e fazer o mundo. Em meio as dificuldades encontradas para permanecer no cursinho e também na universidade, o maior ensinamento que pode ser obtido durantes os três anos que a estudante esteve como aluna foi que a motivação de um grupo de pessoas, que tiveram a experiência de ingressar numa universidade pública, que sabiam dos desencontros existentes entre a formação, suas motivações para que outros tivessem a cesso ao ensino superior. E esses esforços foram e vão além, pois acredito que o objetivo maior desse grupo de pessoas não é somente contribuir com o acesso do estudante à universidade, mas sim possibilitar "a ação e criação de novas formas de engajar-se ao ato de conhecer que constituem um fenômeno relevante as mudanças educacionais necessárias" (KATO, 2011, p.23). Desse mondo, entende-se que há possibilidade de alcançar uma sociedade que se pretende 
democrática, partindo da ideia de superação do ensino "bancário", conteudista para ensino pedagógico que parte do cotidiano dos próprios educandos.

\section{REFERÊNCIAS BIBLIOGRÁFICAS}

CASTRO, C. A. Cursinhos alternativos e populares: movimentos territoriais de luta pelo acesso ao ensino público superior no Brasil. Dissertação (Mestrado em Educação) - Faculdade de Ciências e Tecnologia, Universidade Estadual Paulista "Júlio de Mesquita Filho", Presidente Prudente, 2005.

COTA, M. C. De professores e carpinteiros: encontros e desencontros entre teoria e prática na construção da prática profissional. Educação e Filosofia, v.14, n. 27/28, 2000, p. 203-222.

OLIVEIRA, M. W. (et al.). Processos educativos em práticas sociais: reflexões teóricas e metodológicas sobre a pesquisa educacional nos espaços sociais. Anais da 32a Reunião da ANPED. 2009. Disponível em: <http://www.anped.org.br/reunioes/32a/arquivos/trabalgos/GT06-5383Int.pdf>. Acesso em: mai. 2015

KATO, D. S. O papel dos cursinhos populares nos acessos e mudanças de perspectivas de seus participantes. Revista Eletrônica Cadernos CIMEAC, Ribeirão Preto, v. 1, n. 1, 2011, p. 5-24. 